Received: 28 April 2020

Accepted: 3 June 2020

Online: 15 June 2020

Authors:

P. Sharma $@$ M. C. Kamboj, M. Chand,

R. K. Yadava

Chaudhary Charan Singh Haryana Agricultural

University, Hisar, India

@sharmapreeti.genetics@gmail.com

Emer Life Sci Res (2020) 6(1): 50-55

E-ISSN: 2395-6658

P-ISSN: 2395-664X

DOI: https://doi.org/10.31783/elsr.2020.615055

\section{Research Article \\ Genetic diversity analysis for grain yield and associated traits in advanced lines of bread wheat}

\author{
Preeti Sharma, Mehar Chand Kamboj, Mehar Chand, R. K. Yadava
}

\begin{abstract}
The grouping of 170 wheat genotypes with a variable number of advanced lines into 9 clusters Genetic diversity analysis of 170 genotypes into 9 clusters with variable number of advanced lines on genetic diversity analysis indicated the presence of a considerable amount of genetic diversity in the material. Cluster V was the largest as about 29 advanced lines belonged to this cluster followed by cluster I that possessed 27 RILs whereas cluster $1 \mathrm{X}$ was the smallest comprised of 10 advanced lines. The average intra-cluster distance between the advanced lines was maximum for cluster IV followed in descending order by clusters II, VI, VII, IX, VIII, V, III whereas cluster I exhibited the least intra-cluster distance. The inter-cluster distances was maximum between clusters II vs. VII followed by cluster IV vs. VII and VI vs. VII and was least for cluster I vs. II. The identification of promising genotypes for the improvement program in bread wheat revealed that RIL- 91from cluster IV was promising for plant height and number of spikelets per spike. RIL- 31 from cluster VII were found better for the number of grains per spike and grain yield per plant. RIL- 45 from cluster VIII could be explored for maximum hundred hundred-grain weight and minimum days to 50 percent heading as well. The maximum percent contribution towards the total genetic divergence was indicated for grain weight per spike followed by grain yield per plant, hundred hundred-grain weight, and plant height. Grain yield can be improved through direct selection for effective tillers per plant, a number of grains per spike, and hundred hundred-grain weight in advanced lines of wheat.
\end{abstract}

Keywords bread wheat, genetic diversity, recombinant inbred lines, yield

\section{Introduction}

Wheat continues to retain pride in place among cereals due to its wide adaptation to various agro agro-climatic conditions. It also commands the prominent position in the international market for grain trade. In India wheat is the second most important food crop next to rice and is produced under conditions ranging from the temperate zone of Himalayan foot hills to the subtropical hot areas of central and southern India. The option for increasing wheat production by expanding the area under its cultivation has been exploited to almost its maximum and hence the only alternative left is to increase per unit production of the wheat plant through genetic improvement. So, continuous efforts are to be made to develop high yielding wheat genotypes. As for many field crops, the studies regarding the understanding and improvement of wheat are being conducted by the routine analysis of the genetic diversity among the genotypes because grain yield is a complex trait and is highly influenced by many genetic factors and environmental 
fluctuations. Wheat breeders around the world utilize advanced lines and released varieties in cross more often than the other type of germplasm [1]. The extent of genetic variability in particular decides the efficacy of selection. The search for individual differences plays a significant role in improving the yield and quality of the crop through searching of for new and diverse genetic resources. Genetic divergence is a process of one species diverging over time into more than one species i.e passing small random advantages characteristics changes over time from one generation to the next generation. The concept of D2 statistic is based on the technique of utilizing measurements in respect of an aggregate of characters and this is used as a tool for estimating genetic divergence by plant breeders [2-3]. For this, the RILs have been considered more convenient to develop besides being permanently segregation in the sense that a kind of F2 segregation is regularly maintained year after year without any change in the genetic makeup of the population, so RILs are the immortal population that are is best suited for detailed genetic information regarding gene tagging, genome organization and evolutionary studies as well as improved selection activity in many plant species [4]. Plant breeders are always interested in assessing the genetic diversity among the varieties or advanced breeding material available with them [5]. Therefore the present study has been planned to assess genetic diversity in 170 advanced lines derived using single seed descend approach from the population HD 2204-Redpole of bread wheat in the department by realizing the importance and need for the study of genetic diversity in advanced lines with the main objective to assess the genetic divergence for the morphological traits and yield in advanced lines of wheat. The analysis of genetic relationships in advanced lines of wheat serves to provide information about genetic diversity and is an important component for a stratified sampling of breeding material. Therefore it was imperative to analyze the genetic diversity in this wheat population.

\section{Methodology}

The present investigation was conducted at the experimental area of the Department of Genetics, CCSHAU, Hisar. The advanced homozygous lines were sown in a single row plot for each genotype with four replications (5- tier in each replication) under a randomized block design. Single row plots of $3 \mathrm{~m}$ length, spaced 10, and $30 \mathrm{~cm}$ as intra row and inter inter-row, respectively was used. Field observations on 5 randomly selected competitive plants from each of the advanced lines were recorded for 11 metric traits namely days to 50 per cent heading, plant height $(\mathrm{cm})$, peduncle length $(\mathrm{cm})$, spike length $(\mathrm{cm})$, spikelets per spike, number of effective tillers per plant, spike biomass $(\mathrm{g})$, the weight of grains per spike $(\mathrm{g})$, number of grains per spike, hundred hundred-grain weight $(\mathrm{g})$ and grain yield per plant $(\mathrm{g})$. The data recorded was were analyzed to assess the genetic divergence analysis of grain yield and the morphological traits using the SPSS software package [6].

Table 1. Cluster membership profile of 170 advanced lines of HD2204-Redpole population of bread wheat

\begin{tabular}{|c|l|c|}
\hline Cluster & \multicolumn{1}{|c|}{ Genotypes (No. represents specific advance line) } & Total \\
\hline I & $\begin{array}{l}|c| \\
165,166\end{array}$ & 27 \\
\hline II & $43,67,50,54,78,163,62,87,36,77,108,12,64,70,148,85,74,82,135,76,98,170$ & \\
\hline III & $28,44,66,95,52,155,23,33,92,51,124,35,38,56,55,80,9$ & $17,120,15,137,132,162,73,119,34,42,48,84,59,79,169,88,117,40,69,86$, \\
\hline IV & $72,116,129,94,128,143,103,125,91,140,93$ & 11 \\
\hline V & $\begin{array}{l}3,138,71,157,107,123,7,101,150,111,90,130,89,1,65,68,134,156,167,5,24,25,121,151, \\
\end{array}$ & 29 \\
\hline VI & $41,154,126,159,142,122,161,127,139,131,49,141,112,75,168,147$ & 16 \\
\hline VII & $4,20,30,105,164,6,13,37,11,29,31,60,113,58,8,102,19,158$ & 18 \\
\hline VIII & $14,46,22,47,16,17,45,21,57,26,81,63,99,27,18,97,160,106,53,61$ & 20 \\
\hline IX & $100,109,110,144,114,115,118,133,145,32$ & 10 \\
\hline
\end{tabular}




\section{Results and Discussion}

The cluster analysis of 170 genotypes into 9 clusters following Ward's minimum variance with a variable number of advanced lines is presented in Table 1 which indicated the presence of a considerable amount of genetic diversity in the material. Cluster $\mathrm{V}$ was the largest as about 29 advanced lines belonged to this cluster followed by cluster I that possessed 27 RILs whereas Cluster VI, IV, and IX comprised of less than 10 per cent of the RILs.

\section{Intra and inter inter-cluster distances}

The intra- and inter- cluster distance values between 9 clusters are presented in Table 2 . which revealed that the intra-cluster distance for the RILs that comprised cluster IV, had the maximum divergence and it was followed by cluster II, VI, VII, IX, VIII whereas cluster I indicated the least intra-cluster distance for the 27 RILs belonging to this cluster. The results are in agreement with earlier findings of Roy et al., Singh et al., Iqubal et al., Verma et al., [7-10], who also reported maximum divergence in wheat. The crosses between the genotypes belonging to distantly located clusters are likely to produce transgressive segregants.

Table 2. Estimates of intra (diagonal) and intercluster distances in advanced lines of HD2204-Redpole population

\begin{tabular}{|l|l|l|l|l|l|l|l|l|l|l|}
\hline Cluster & I & II & III & IV & V & VI & VII & VIII & IX \\
\hline I & $\mathbf{3 . 0 4 5}$ & 4.011 & 4.197 & 4.511 & 4.258 & 4.342 & 5.262 & 4.492 & 4.466 \\
\hline II & - & $\mathbf{3 . 7 8 6}$ & 4.898 & 5.277 & 4.990 & 4.997 & 6.215 & 5.435 & 5.220 \\
\hline III & - & - & $\mathbf{3 . 4 9 9}$ & 4.781 & 4.358 & 5.135 & 4.351 & 4.409 & 4.774 \\
\hline IV & - & - & - & $\mathbf{4 . 3 5 5}$ & 5.138 & 5.036 & 5.692 & 5.544 & 5.415 \\
\hline V & - & - & - & - & $\mathbf{3 . 6 7 5}$ & 4.398 & 4.936 & 4.410 & 4.834 \\
\hline VI & - & - & - & - & - & $\mathbf{3 . 7 7 7}$ & 5.594 & 5.326 & 5.093 \\
\hline VII & - & - & - & - & - & - & $\mathbf{3 . 7 7 6}$ & 4.277 & 4.814 \\
\hline VIII & - & - & - & - & - & - & - & $\mathbf{3 . 6 9 6}$ & 4.807 \\
\hline IX & - & - & - & - & - & - & - & - & $\mathbf{3 . 7 3 6}$ \\
\hline
\end{tabular}

The inter-cluster distances was were observed to be maximum between cluster II vs VII, and it was followed by cluster IV vs VII and cluster VI vs VII. The higher intercluster distances exhibit the presence of more diversity among the genotypes involving these clusters. Mainly cluster IV, VII, VIII, VI, II, and IX are indicated as having higher inter-cluster distances. The least intercluster distance has been noticed for Cluster I vs II. Nimbalkar et al., [11] have reported generalized distances for the 24 wheat cultivars when observed for yield and its contributing traits and they could group them into 12 clusters. Dwivedi and Pawar [12] while evaluating 72 lines of bread wheat for 12 yield and other quality attributes have found the distribution pattern of genotypes in different clusters as a random event with little association between genetic divergence and agro agro-ecological distribution of genotypes. Kumar et al., [13] could group 30 genotypes of wheat into 6 clusters based on observation on 6 characters. Yadav et al., Kumar et al., Shyam et al., [14-16] observed diversity with high range of values of inter and intra cluster distance among wheat genotypes

\section{Mean values of different clusters for various traits}

Cluster means and general mean values in the Table 3 revealed that differences in the cluster means, existed for all the characters studied. The genotypes with high values of any cluster can be used in the hybridization programme for further selection and improvement. The cluster I was characterized as though having above above-average values for the number of tillers per plant and hundred hundred-grain weight but not for any of the traits as having magnitude to the desired extent. Hence from this cluster, none of the 
Table 3. Cluster means and average (overall) for morphological traits in advanced lines of HD2204-Redpole population of bread wheat

\begin{tabular}{|c|c|c|c|c|c|c|c|c|c|c|c|}
\hline Cluster & $\begin{array}{l}\text { PH } \\
(\mathrm{cm})\end{array}$ & NSS & $\begin{array}{l}\text { PL } \\
(\mathrm{cm})\end{array}$ & $\begin{array}{l}\text { SL } \\
(\mathrm{cm})\end{array}$ & NGPS & TPP & DH & $\begin{array}{l}\text { SW } \\
(\mathrm{g})\end{array}$ & $\begin{array}{l}\text { GWPS } \\
\text { (g) }\end{array}$ & $\begin{array}{l}\text { HGW } \\
(\mathrm{g})\end{array}$ & $\begin{array}{l}\text { YPP } \\
(\mathrm{g}) \\
\end{array}$ \\
\hline I & 117.398 & 21.722 & 46.222 & 10.310 & 40.630 & 9.143 & 84.426 & 2.510 & 1.898 & 4.319 & 16.167 \\
\hline II & 112.420 & 21.705 & 45.132 & 11.172 & 40.784 & 7.639 & 84.091 & 2.517 & 1.924 & 3.194 & 10.217 \\
\hline III & 115.176 & 23.676 & 45.750 & 11.632 & 51.971 & 8.279 & 84.853 & 2.936 & 2.254 & 4.485 & 18.302 \\
\hline IV & 101.818 & 23.273 & 47.309 & 11.932 & 41.318 & 9.818 & 89.091 & 2.610 & 2.023 & 4.407 & 19.153 \\
\hline $\mathrm{V}$ & 133.638 & 22.310 & 54.193 & 11.700 & 45.836 & 8.403 & 86.129 & 2.796 & 2.172 & 4.302 & 15.891 \\
\hline VI & 130.047 & 21.750 & 52.272 & 12.703 & 43.000 & 10.353 & 86.547 & 2.251 & 1.707 & 3.730 & 18.356 \\
\hline VII & 121.417 & 22.056 & 49.414 & 12.615 & 53.764 & 10.189 & 83.500 & 3.197 & 2.525 & 4.515 & 26.773 \\
\hline VIII & 123.488 & 20.525 & 50.608 & 11.966 & 44.725 & 8.997 & 82.613 & 3.209 & 2.460 & 4.804 & 19.972 \\
\hline IX & 120.975 & 21.100 & 49.085 & 9.765 & 48.075 & 11.530 & 84.975 & 2.969 & 2.379 & 3.308 & 20.629 \\
\hline Average & 120.837 & 21.976 & 49.056 & 11.528 & 45.250 & 9.127 & 84.938 & 2.766 & 2.135 & 4.156 & $\mathbf{1 7 . 7 9 6}$ \\
\hline $\mathrm{CD}(5 \%)$ & 7.64 & 1.32 & 5.31 & 0.61 & 5.15 & 0.80 & 1.66 & 0.32 & 0.25 & 0.22 & 1.51 \\
\hline $\mathrm{CD}(1 \%)$ & 10.05 & 1.73 & 6.99 & 0.80 & 6.77 & 1.05 & 2.17 & 0.42 & 0.32 & 0.30 & 1.99 \\
\hline $\begin{array}{l}\text { Percent } \\
\text { contributio } \\
\text { n towards } \\
\text { variability }\end{array}$ & 11.90 & 1.06 & 0.13 & 6.77 & 0.27 & 3.22 & 2.13 & 0.77 & 51.12 & 13.70 & 18.93 \\
\hline
\end{tabular}

advanced lines may be suitable for genetic improvement for any of the traits studied. Cluster II however indicated none of the above above-average values for any of the characters studied but may be considered for the genetic improvement focused on dwarfing of bread wheat genotypes. Cluster III was characterized for the number of spikelets per spike, number of grains per spike, and hundred hundred-grain weight in particular being above average in this cluster. Cluster IV was characterized by above aboveaverage values for the number of spikelets per spike, days to 50 per cent heading, hundred hundred-grain weight, and grain yield per plant.

Cluster V had above above-average values for plant height and number of spikelets per spike. Similarly, Cluster VI indicated above average for plant height, spike length, and tillers per plant. Cluster VII was characterized for above above-average values for spike length, number of grains per spike, tillers per plant, spike weight, grain weight per spike, hundred hundred-grain weight, and grain yield per plant. Cluster VIII recorded maximum average values for spike weight, grain weight per spike, a hundred hundred-grain weight, and grain yield per plant. Cluster IX exhibited as having above above-average values for the number of effective tillers per plant, grain yield per plant, and grain weight per spike. These results are in conformityconform with those obtained by Hailegiorgis et al., [17], Yadav et al., [14], Kumar et al., [15], Pandey et al., [18] Shyam et al., [16] for grain yield.

The per cent contribution of various characters towards the total genetic divergence indicated that grain weight per spike, grain yield per plant, hundred hundred-grain weight, and plant height contributed maximum towards the total divergence in the present study. However, Chapla et al., [5] reported maximum contribution of various characters towards the total genetic divergence for the characters viz., grain weight per spike, length of the main spike, days to 50 per cent flowering and peduncle length which together account for more than $80 \%$ of the total divergence in the material studied. Cluster means also revealed that plant height had the maximum contribution to genetic divergence and Bergale et al., [19] report has been in agreement to with the contribution towards genetic divergence, where plant height had the greatest contribution. Genotypes with better mean values can be selected from the appropriate clusters to suit the breeding programme.

Further, the identification of promising genotypes for the improvement programme in bread wheat in Table 4 revealed that none of the recombinant inbred lines from cluster I appeared promising for any of the traits where the magnitude have has been around the overall mean for the characters recorded. RIL- 91 from cluster IV was promising for plant height and number of spikelets per spike. RIL- 31 from cluster VII were found better for the number of grains per spike and grain yield per plant. RIL- 45 from cluster VIII 
could be explored for maximum hundred hundred-grain weight and minimum days to 50 per cent heading as well.

Table 4. List of advanced lines of HD2204-Redpole population identified for desired attribute(s) from various clusters

\begin{tabular}{|c|l|l|}
\hline Cluster & Suggested genotypes (RILs) & Desired attribute present \\
\hline I & - & - \\
\hline II & RIL-78, RIL-50 & Plant height \\
\hline III & RIL-52 & Number of grains per spike \\
\hline IV & RIL-91, RIL-129, RIL-93 & Plant height, NSS \\
\hline V & RIL-153, RIL-24, RIL-101 & Peduncle length \\
\hline VI & RIL-122, RIL-154 & Spike length \\
\hline VII & RIL-31, RIL-60, RIL-102, RIL-31, RIL-8, RIL-11 & NGPS, YPP, SL \\
\hline VIII & RIL-16, RIL-45, RIL-18, RIL-61, RIL-45 & DH, SW, GWPS, HGW \\
\hline IX & RIL-114, RIL-109, RIL-100 & TPP \\
\hline
\end{tabular}

Based on the above findings, it is concluded that for further genetic improvement for grain yield, the emphasis be is put for the studies on physiological aspects and molecular basis. The stem elongation traits and the spike attributes may be considered of particular interest for further breakthrough in the grain yield in bread wheat. It is suggested that grain yield can be improved through direct selection for effective tillers per plant, the number of grains per spike, and hundred hundred-grain weights in advanced lines of wheat. However, grain yield being a complex trait it is pertinent to have a more detailed analysis on of physiological aspects and also on the genetic basis at the molecular level involving the present advanced lines.

\section{References}

[1] D. M. Rejesus, M. V. Ginkel and M. Smale (1996). Wheat breeder's perspectives on genetic diversity and germplasms use: Findings from an international Survey wheat programme special report CIMMYT, Mexico, D.F. Mexico: pp. 40.

[2] P. C. Mahalanobis (1936). On the generalized distance in statistics. National Institute of Science of India.

[3] C. R. Rao (1952). Advanced statistical methods in biometrical research. John Wiley and Sons, New York, USA., 351-382

[4] A. H. Paterson, S. D. Tanksley and M. E. Sorrells (1991). DNA markers in plant improvement. Adv. Agron., 46: 39-90.

[5] J. N. Chapla, K. L. Dobaria, M. D. Khanpara, L. L. Jivani and V. H. Kacchadia (2008). Genetic divergence in bread wheat (Triticum aestivum L.). Natnl. J. Plant Improv., 10: 97-102.

[6] SPSS Inc. (1991). SPSS statistical algorithms. SPSS Incorporated.

[7] J. K. Roy, M. S. Lakshmikumaran, , H. S. Balyan and P. K. Gupta (2004). AFLP based genetic diversity and its comparison with diversity based on SSR, SAMPL and phenotypic traits in bread wheat. Biochem. Genet., 42: 43-59.

[8] S. K. Singh, B. N. Singh, P. K. Singh and C. L. Sharma (2006). Genetic divergence of exotic germplasm lines in wheat (T. aestivum L.). Indian J. Plant Genet. Res., 19: 218-220.

[9] A. Iqubal, A. S. Khan, I. A. Khan, F. S. Awan, A. Ahmad and A. A. Khan (2007). Study of genetic divergence among wheat genotypes through random amplified polymorphic DNA. Genet. Mol. Res., 6: 476-481.

[10] P. N. Verma, B. N. Singh, G. Singh, M. K. Singh and T. L. Setter (2014). Genetic diversity analysis for yield and other agronomic traits in bread wheat under water logged sodic soil condition. J. Wheat Res., 6: $51-58$.

[11] C. A. Nimbalkar, P. A. Navale, and A. B. Biradar (2002). Generalized D2 and genetic diversity in wheat. J. Maharashtra Agric. Univ., 27: 43-45. 
[12] A. N. Dwivedi and I. S. Pawar (2005). Evaluation of genetic diversity among wheat germplasm lines for yield and quality attributing traits in bread wheat. Haryana Agric. Univ. J. Res., 34: 35-39.

[13] B. Kumar, R. G. M. Lal and A. Upadhyay (2009). Genetic variability, diversity and association of quantitative traits with grain yield in bread wheat (Triticum aestivum L.). Asian J. Agric. Sci., 1: 4-6.

[14] S. K. Yadav, A. K. Singh, S. S. Baghel, M. Jarman and A. K. Singh (2014). Assessment of genetic variability and diversity for yield and its contributing traits among CIMMYT based wheat germplasm. J. Wheat Res., 6: 154-159.

[15] R. Kumar, B. K. Prasad, M. K. Singh, G. Singh and A. Verma (2015). Genetic divergence analysis for morphophysiological traits, under timely and late sown condition in bread wheat (Triticum estivum L.). J. Wheat Res., 7: 27-30.

[16] C. Shyam, P. K. Chandrakar, N. K. Rastogi and U. Banjare (2018). Evaluation of Genetic Divergence Analysis in Wheat for Yield and its Component Characters. Int. J. Agric. Environ. Biotech., 11: 829834.

[17] D. Hailegiorgis, M. Mesfin and T. Genet (2011). Genetic divergence analysis on some bread wheat genotypes grown in Ethiopia. J. Cent. Europ. Agric., 12: 344-352.

[18] M. K. Pandey, H. N. Bind, S. Kumar and B. N. Singh (2017). Genetic divergence in wheat (Triticum aestivum L. Thell.) under saline sodic condition. Int. J. Curr. Microbiol. App. Sci., 6: 181-189.

[19] S. Bergale, B. Mridula, A. S. Holkar, K. N. Ruwali and S. V. S. Prasad (2001). Pattern of variability, character association and path analysis in wheat (Triticum aestivum L.). Agric. Sci. Digest., 22: 258-260. 